\title{
COMPARISON OF MECHANICAL AND MICROSTRUCTURAL EXAMINATION OF AL7075 COMPOSITES REINFORCED WITH MICRO AND NANO $\mathrm{B}_{4} \mathrm{C}$
}

\author{
Krishna Mohan Singh and A. K. Chauhan \\ Department of Mechanical Engineering, KNIT, Sultanpur, U.P. 228118, India
}

\begin{abstract}
Due to the demand for lightweight materials in the field of automobiles, aeronautics and some other application, there is a need to develop lightweight materials. For the last few decades, aluminum matrix composites are being developed in order to meet out the demand of the above-mentioned industries. aluminum the above, lightweight material in the form of composites of $B_{4} C$ reinforced in Al7075 alloy is considered for the present investigation. The composite was produced using the stir casting method. In this investigation, the micro and nano ${ }_{4} C$ particles were used as reinforcements. The fabricated composites were characterized for microstructure and mechanical properties. From the microstructural examination, it was observed that $12 \%$ of $\mathrm{B}_{4} \mathrm{C}$ nanocomposites was having fine microstructure as compared to others. The hardness and strength were found to be maximum for $12 \% B_{4} C$ nanocomposites which impact strength was lowest for $12 \%$ micro composites.
\end{abstract}

Keywords: Al7075 alloy, B4Cp, Stir casting, and UTS.

Cite this Article: Krishna Mohan Singh and A. K. Chauhan, Comparison of mechanical and microstructural examination of A17075 composites reinforced with micro and nano $\mathrm{B}_{4} \mathrm{C}$, International Journal of Mechanical Engineering and Technology 11(4), 2020, pp. 08-15

https://iaeme.com/Home/issue/IJMET?Volume=11\&Issue $=4$

\section{INTRODUCTION}

Aluminum matrix composites are being used in various fields such as automobiles, aerospace marine, etc. due to their favorable properties [1]. An alloy of the Al7075 series is having the highest strength to weight ratio. This properly makes Al7000 series alloys a good option for reinforcement. The reinforcement can be a ceramic oxide, nitride carbide particulates. These reinforcements are improving the properties of Al7000 series alloys[2],[3],[4]. In an investigation, Al7075 alloy was reinforced with LM 13 aluminum/ $\mathrm{B}_{4} \mathrm{C}$ by means of liquid metallurgy techniques to find the wear behavior[5]. V. Ramakoteswara Rao et al[6] have synthesized Aluminium matrix composites reinforced with titanium carbide particles to find the sliding wear behavior. E. Zalenhad and A.D. Sachan investigated fretting fatigue resistance of A17075-T6 with surface treatment of Ti-TiN multilayer coating[7]. 
From most of the investigation done by various researchers, it was observed that the composite of the Al7000 series is made by casting technique[8]. Harichandran and Selvakumar instigated that mechanical properties such that impact energy was higher in composites having nano reinforcement as compared to composites having micro reinforcement[9]. Daniel et al [10] having investigated the influence of wt. percentage of $\mathrm{SiC}$ particles reinforced in aluminum metal matrix composites. Nagral et al[11] have reported that A12024 alloy composites were manufactured with $\mathrm{B}_{4} \mathrm{C}$ particles using a stir casting technique. Singh and Chuahan[12] have reported about the second generation of composites. They reported that hybrid aluminum matrix composites are belonging to second-generation composites. According to the second generation, composites have substantial potential as an alternative to Singh reinforced composites. AA7075 matrix was reinforced with $\mathrm{TiC}$ particles through the stir casting technique[13]. The investigators found the effect of load on the friction and wear of matrix as well as composites. In a research paper, the authors developed a statistical model to envisage vibration amplitude[14]. Dhokey and Rane have applied aluminum-based $\mathrm{TiB}_{2}$ reinforced composites as brake drum material. They observed that the wear behavior of the composites was considerably good in correlation with its mechanical properties[15].

In the present investigation A17075 alloy has been used as a matrix. This was reinforced with micro and nano $\mathrm{B}_{4} \mathrm{C}$ particles. The composites were characterized in terms of microstructure and mechanical properties,

\section{MATERIALS}

A17075 alloy was selected as a composites matrix. micro and nano $\mathrm{B}_{4} \mathrm{C}$ chosen for the fabrication of the composites reinforcement particle. The composites were manufactured by stir casting techniques. The A17075 alloy framework made of A17075 was melted in a vacuum furnace for the preparation of the composites. After passing through a sieve for each composite, weighted and preheated dispersoids of size between $50 \mu \mathrm{m}$ and $90 \mathrm{~nm}$ with $6,8,10 \& 12$ weight $\%$ were poured into the melt. The melt was continuously stirrer during the insertion of the dispersoid, using a stirrer put in the melt driven by a motor.

\section{STIR CASTING TECHNIQUES}

The vacuum furnace (Fig.1) was used to produce the composites. A scattered phase (micro and nano $\mathrm{B}_{4} \mathrm{C}$ particles) was inserted in molten metal. The stir was used to uniformly distribute the reinforcement particles.

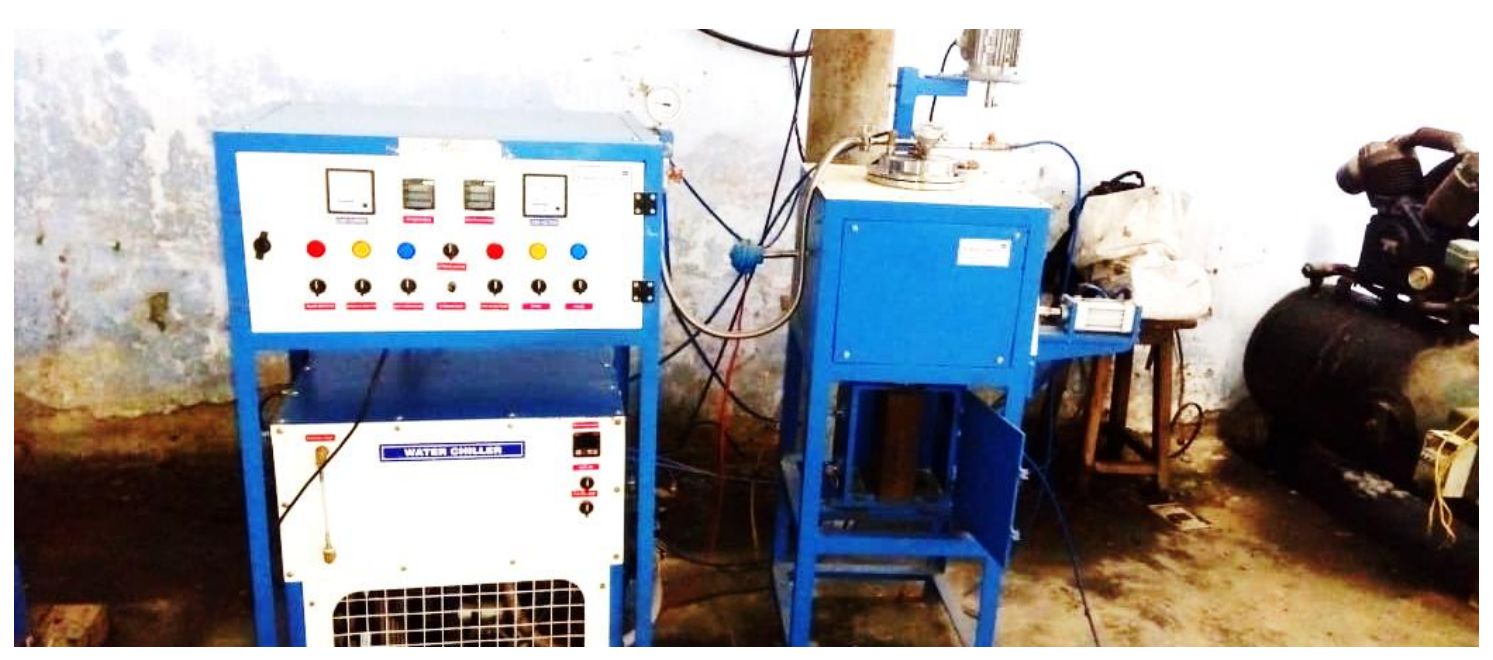

Figure 1 Experimental setup for fabricating A17075 and $\mathrm{B}_{4} \mathrm{C}$ particles. 


\section{MICROSTRUCTURAL AND MECHANICAL PROPERTIES}

The microstructure was examined using an optical microscope. XRD spectra were performed on the composites to find the crystal structure. The hardness was measured using a Brinell Hardness Tester. The load and dwelling times applied were $187.5 \mathrm{kgf}$ and $5 \mathrm{~s}$, respectively. Tensile experiments were conducted on a Universal Testing Machine (UTM). The tests were performed as per the ASTM E8 standard. The impact tests were carried out on an impact testing machine. The impact tests were performed as per the ASTM E23 standard.

\section{RESULT AND DISCUSSION}

\subsection{Compositional analysis}

The compositions of the $\mathrm{A} 17075$ and $\mathrm{B}_{4} \mathrm{C}$ are shown in Tables 1 and 2 respectively.

Table 1 Chemical analysis of Al 7075 alloy.

\begin{tabular}{|c|c|c|c|c|c|c|}
\hline Elements & $\mathbf{Z n}$ & $\mathbf{M g}$ & $\mathbf{C u}$ & $\mathbf{F e}$ & $\mathbf{C r}$ & Al \\
\hline \% by wt. & 5.8 & 2.4 & 1.5 & 0.2 & 0.2 & Balance \\
\hline
\end{tabular}

Table 2 Chemical analysis of $\mathrm{B}_{4} \mathrm{C}$ micro powder $(50 \mu \mathrm{m})$ and nanopowder $(90 \mathrm{~nm})$.

\begin{tabular}{|c|c|c|c|c|c|c|c|}
\hline Elements & Assay & Boron & Carbide & $\mathbf{O}$ & $\mathbf{N}$ & $\mathbf{S i}$ & $\mathbf{N i}$ \\
\hline \% by wt. & 99.9 & 77.2 & 22.3 & $<0.1$ & $<0.08$ & $<0.1$ & $<0.01$ \\
\hline
\end{tabular}

\subsection{Microstructural Examination}

Fig. 2, show the microstructure of A17075 and Fig. 3 and Fig. 4, show the microstructure of the Al7075 with micro and nano $\mathrm{B}_{4} \mathrm{C}$ respectively. The analysis of microstructure clearly shows that the surfaces are transparent with few porosities. The investigation into Optical microscope micrographs shows that microstructure consists of a uniform distribution of micro $\mathrm{B}_{4} \mathrm{C}$ particles and intermetallic compounds scattered along the grain boundary in the Al7075 alloy matrix. Uniform micro- and nano $\mathrm{B} 4 \mathrm{C}$ particle dispersal and better bonding within $\mathrm{Al} 7075$ improve the properties.

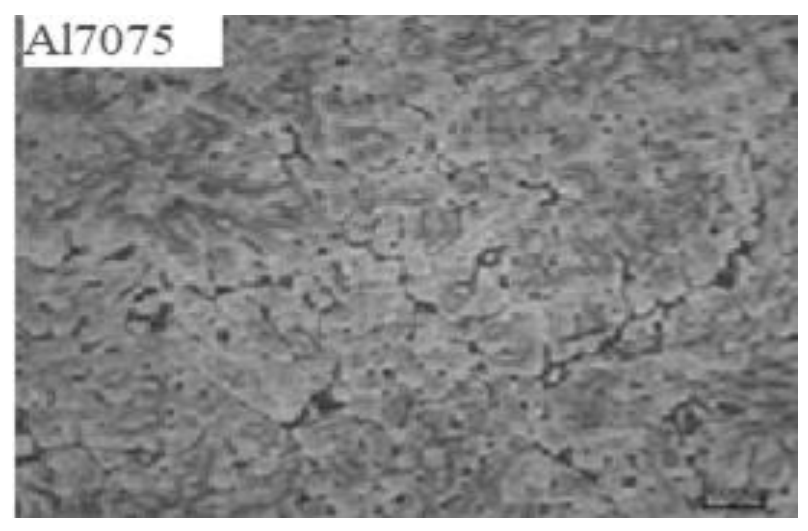

Al7075 alloy

Figure 2 The microstructure of A17075 alloy 

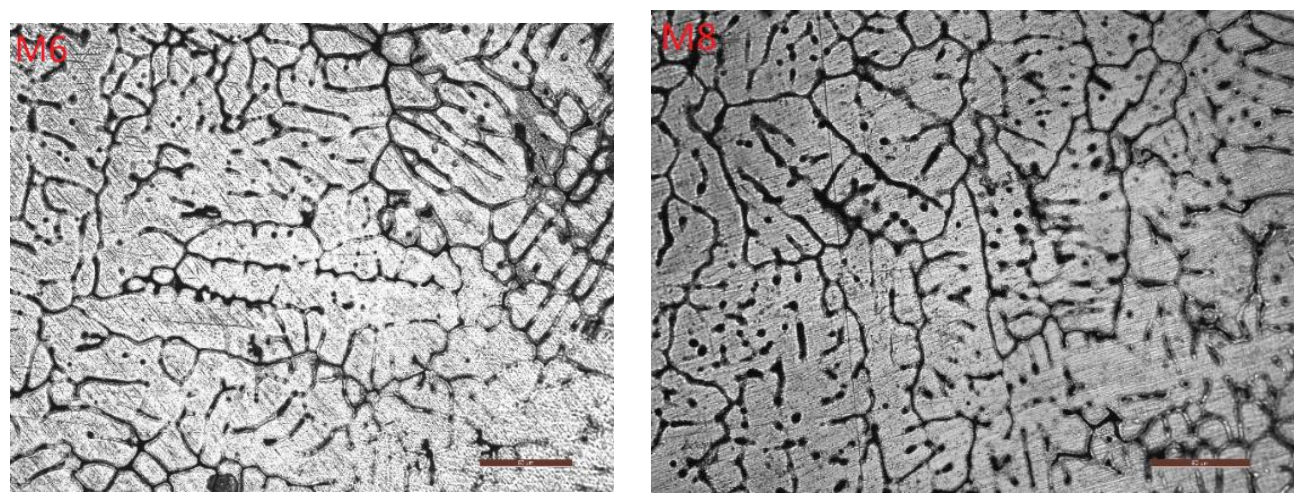

Al7075-6 wt. \% of micro $\mathrm{B}_{4} \mathrm{C}$

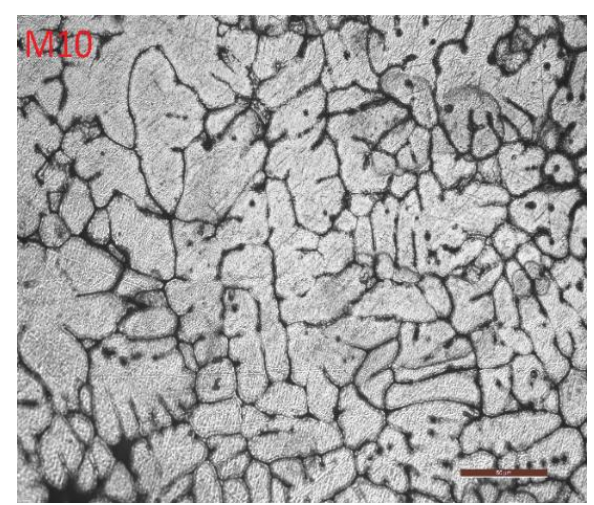

Al7075-10 wt. \% of micro $\mathrm{B}_{4} \mathrm{C}$
Al7075-8 wt. \% of micro $\mathrm{B}_{4} \mathrm{C}$

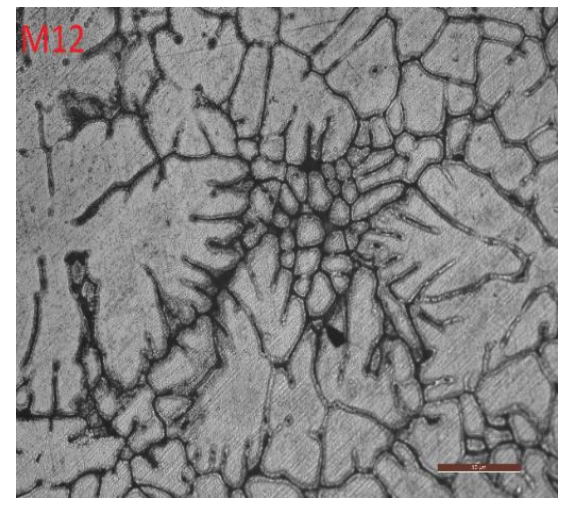

Al7075-12 wt. \% of micro $\mathbf{B}_{\mathbf{4}} \mathbf{C}$

Figure 3The microstructure of Al7075 with micro $\mathrm{B}_{4} \mathrm{C}$.

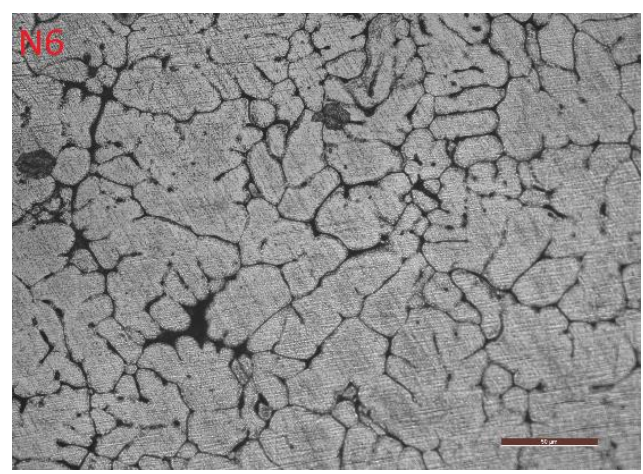

Al7075-6 wt. \% of nano $\mathrm{B}_{4} \mathrm{C}$

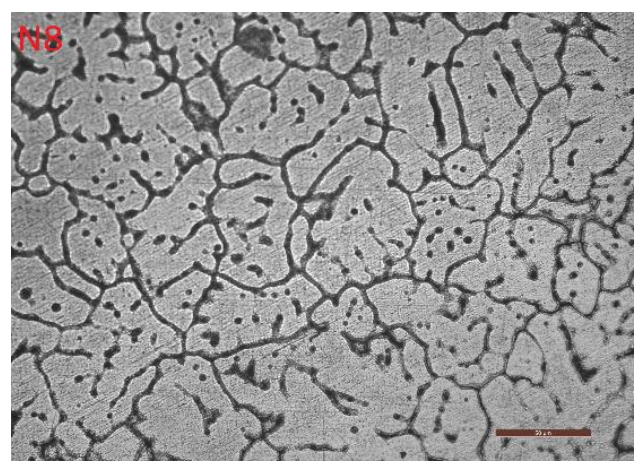

Al7075-8 wt. \% of nano $\mathrm{B}_{4} \mathrm{C}$ 
Comparison of mechanical and microstructural examination of A17075 composites reinforced with micro and nano $\mathrm{B}_{4} \mathrm{C}$

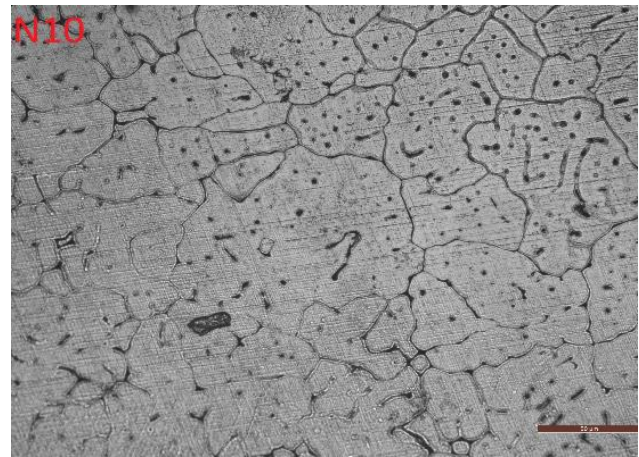

Al7075-10 wt. \% of nano $\mathrm{B}_{4} \mathrm{C}$

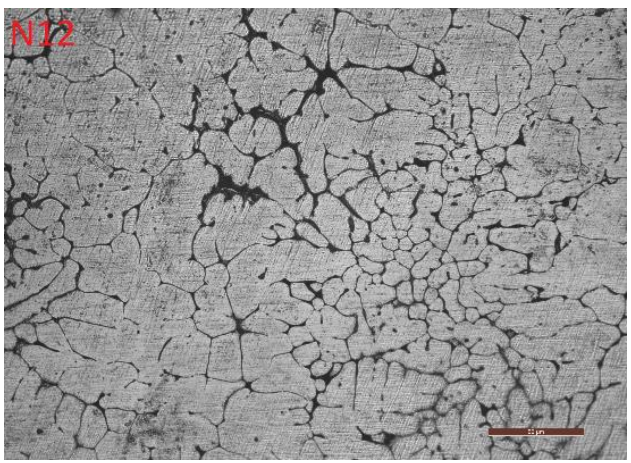

Al7075-12 wt. \% of nano $\mathrm{B}_{4} \mathrm{C}$

Figure 4 The microstructure of Al7075 with nano $B_{4} C$.

\subsection{X-ray diffraction analysis}
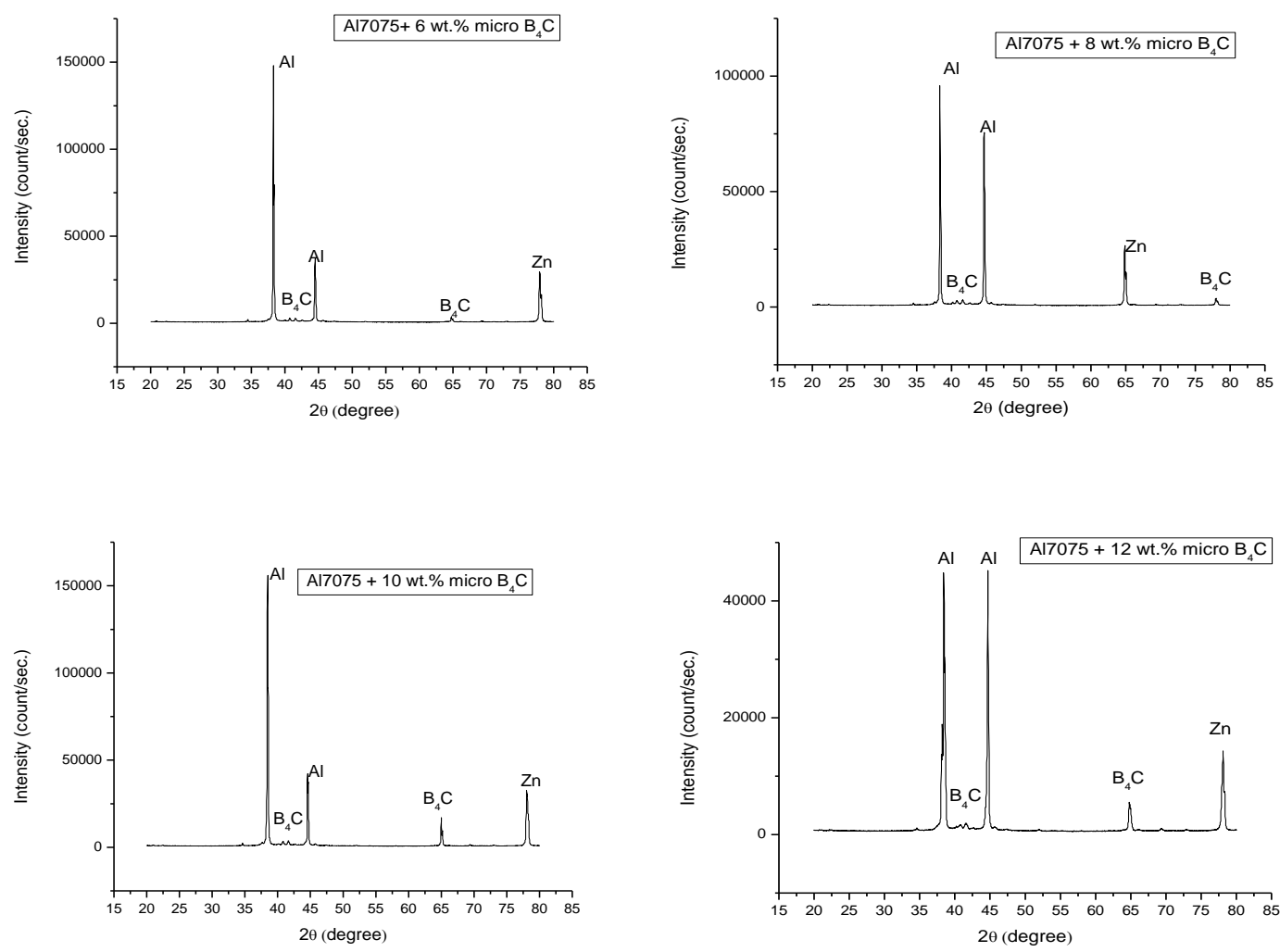

Figure 5 XRD of Al7075 alloy with wt. \% micro $\mathrm{B}_{4} \mathrm{C}$. 

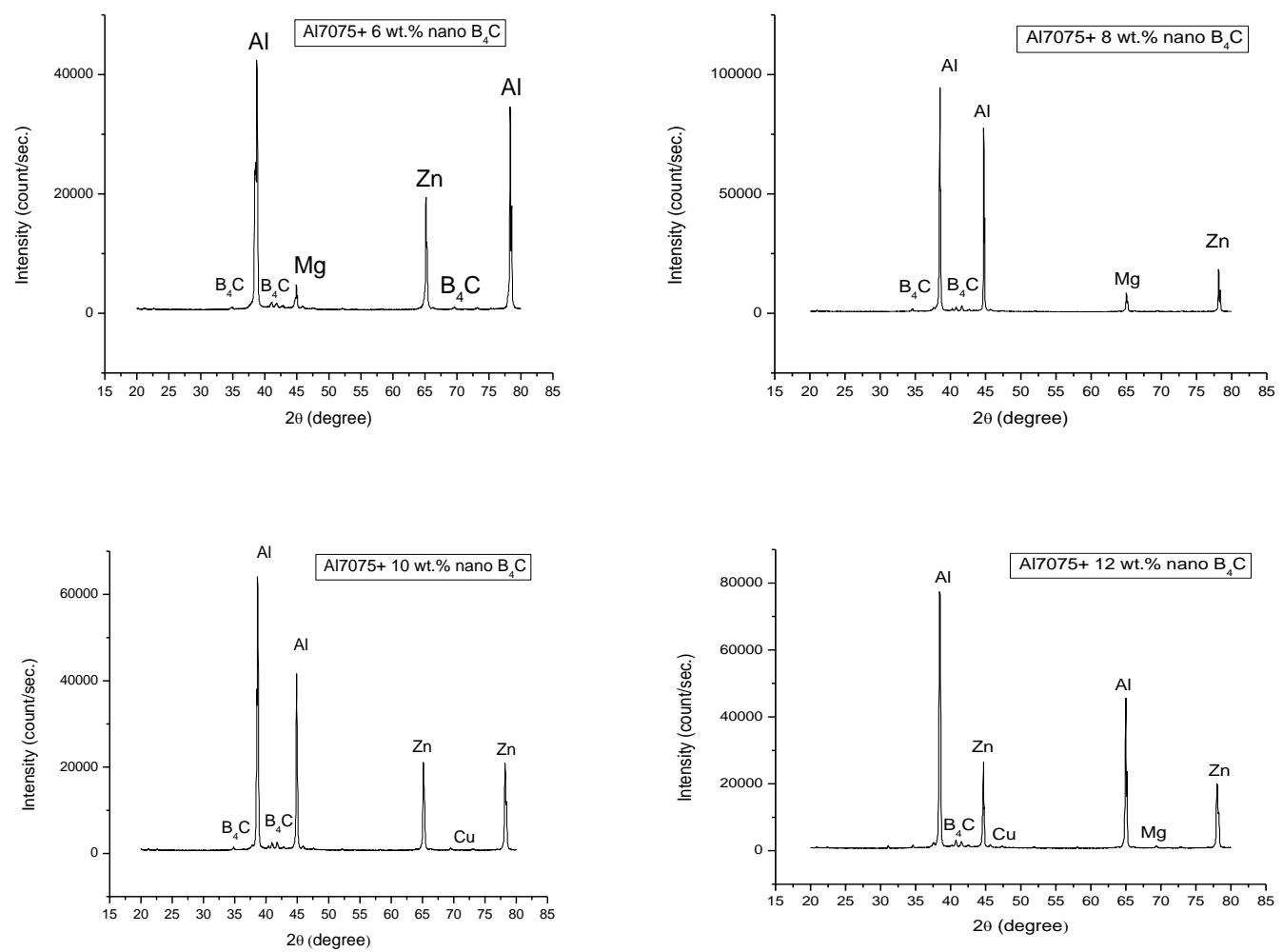

Figure 6 XRD of Al7075 alloy with wt. \% nano $\mathrm{B}_{4} \mathrm{C}$

Fig. 5 and Fig. 6 respectively, indicate X-ray diffraction spectra of as-cast A17075 alloy and reinforced with micro and nano $\mathrm{B}_{4} \mathrm{C}$. The $\mathrm{XRD}$ analysis study reveals that the height of the peak shows the presence of elements as mentioned.

\subsection{Tensile Tests}

Fig. 7 Demonstrates a comparative bar graph of AMCs reinforced with $\mathrm{B}_{4} \mathrm{Cp}$ of $6,8,10$ and 12 $\%$ micro and nano $\mathrm{B}_{4} \mathrm{C}$. The increase in the tensile strength of $\mathrm{AMCs}$ containing nano $\mathrm{B}_{4} \mathrm{Cp}$ is due to the strengthening of the matrix.

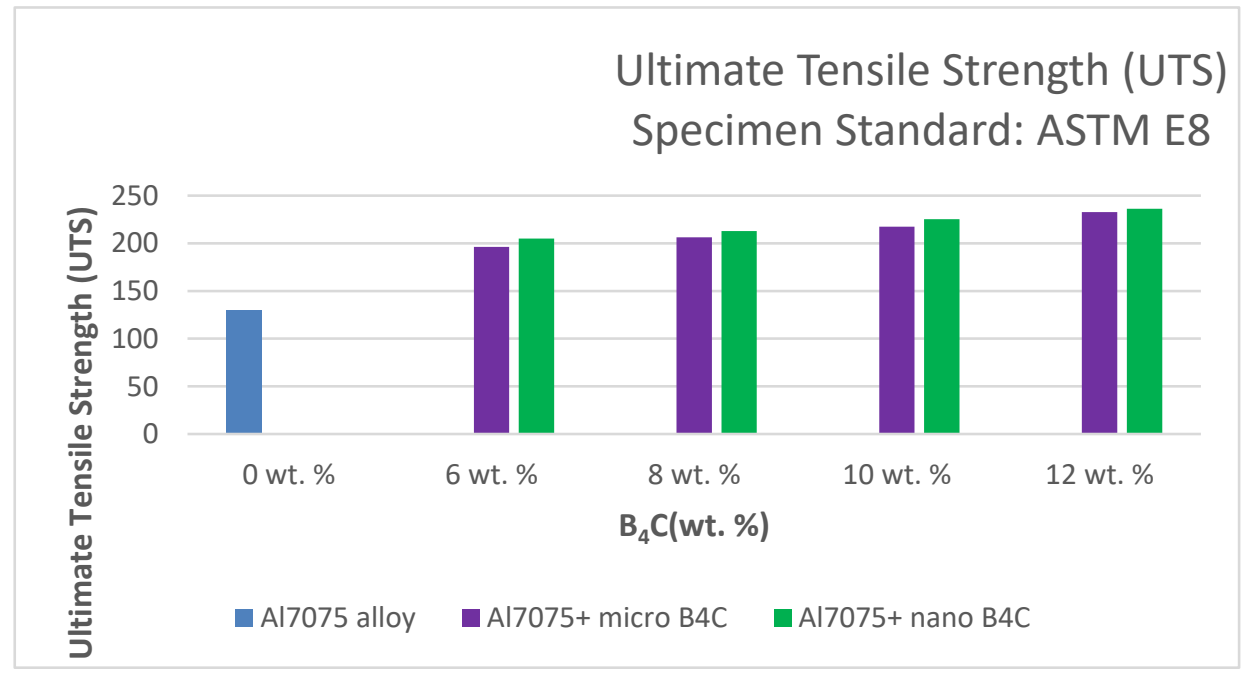

Figure 7 Comparative bar chart for UTS of Al7075 and its composites. 
Comparison of mechanical and microstructural examination of Al7075 composites reinforced with micro and nano $\mathrm{B}_{4} \mathrm{C}$

\subsection{Hardness Test}

Fig. 8 indicates the effect of the particle content of micro and nano $\mathrm{B}_{4} \mathrm{C}$ on the hardness of the micro and nano $\mathrm{B}_{4} \mathrm{C}$ reinforced composites. The values of hardness seem to depend on the weight of micro and nano $\mathrm{B}_{4} \mathrm{Cp}$. The composites made with nano $\mathrm{B}_{4} \mathrm{C}$ are having the same what higher hardness. With the addition of $12 \mathrm{wt} . \%$, the hybrid composites reach optimum hardness.

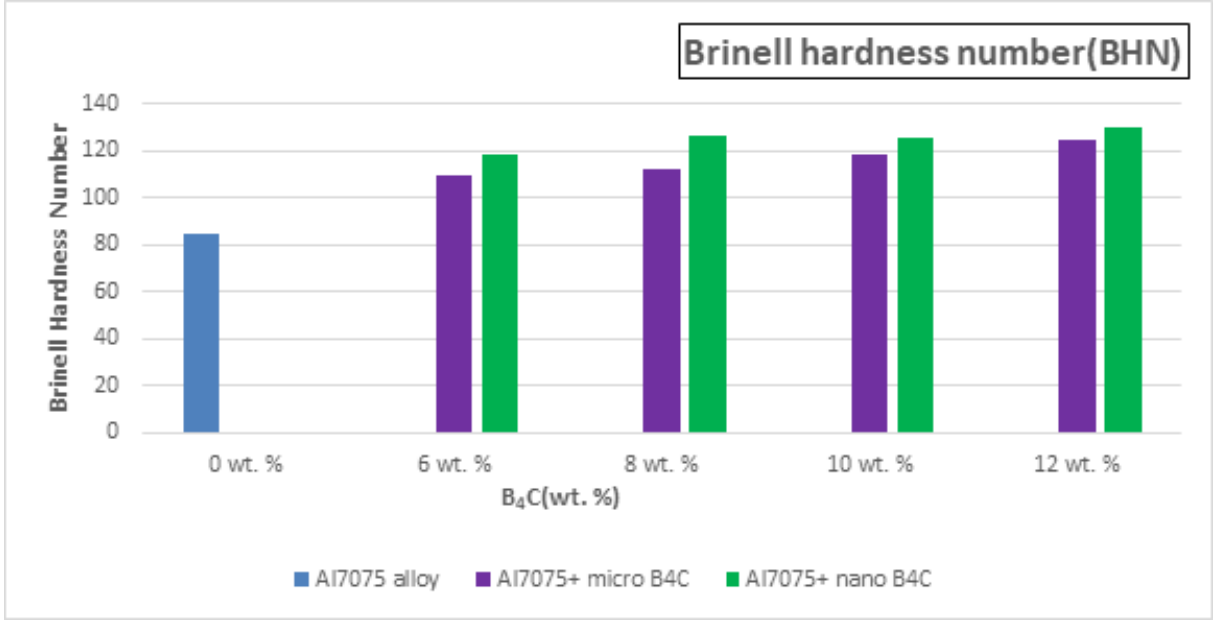

Figure 8 Comparative bar chart for BHN of Al7075 and its composites.

\subsection{Impact test}

The toughness value of the alloy and the composites is shown in Fig. 9. It is observed that there is a decrease in toughness due to an increase in the volume fraction of reinforcements.

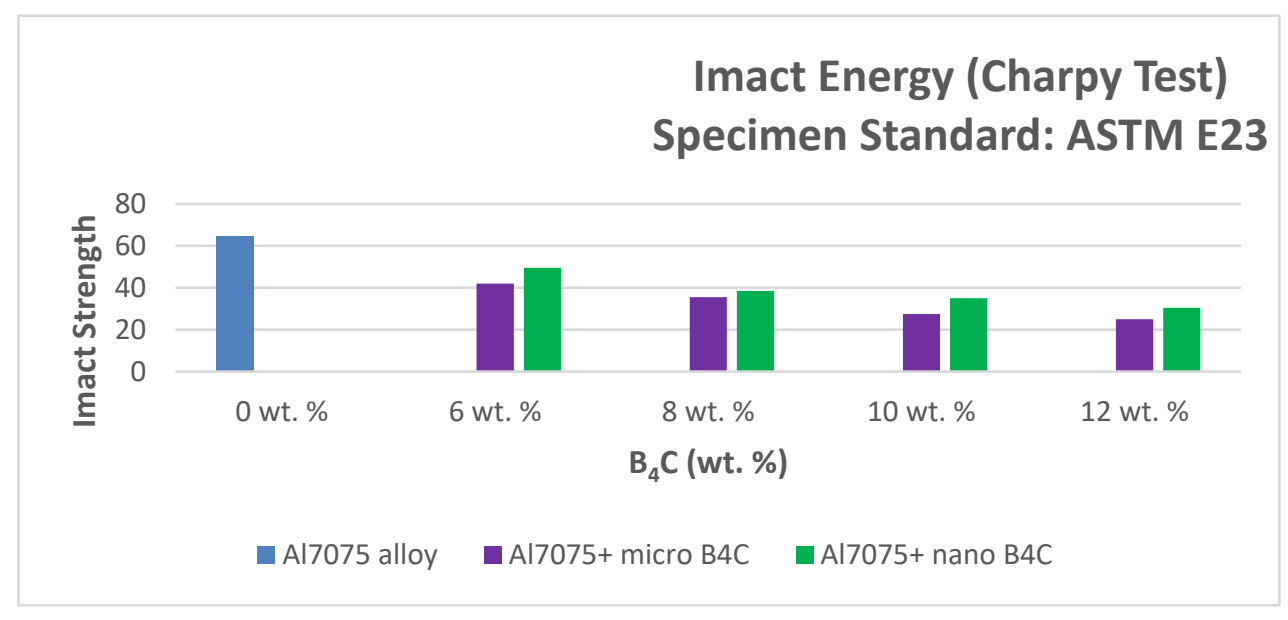

Figure 9 Comparative bar chart for Impact strength of Al7075 and its composites.

\section{CONCLUSIONS}

The micro and nano $\mathrm{B}_{4} \mathrm{Cp}$ reinforced with $\mathrm{A} 17075$ were produced using stir- casting. The composites were examined to investigate the effect of various weight percentages of micro and nano $\mathrm{B}_{4} \mathrm{Cp}$ on the microstructure and mechanical properties of the composites.

The nanocomposites having higher strength than that of micro composite and Al7075 alloy

The impact energy of nano $\mathrm{B}_{4} \mathrm{Cp}$ reinforced aluminum composites was higher than that of micro $\mathrm{B}_{4} \mathrm{Cp}$ reinforced $\mathrm{A} 17075$ composites. 


\section{REFERENCES}

[1] R. K. Bhushan, S. Kumar, and S. Das, "Fabrication and characterization of $7075 \mathrm{Al}$ alloy reinforced with SiC particulates," Int. J. Adv. Manuf. Technol., vol. 65, no. 5-8, pp. 611624, 2013.

[2] P. Kammer, H. K. Shivanand, and S. K. S, “" Experimental Studies on Mechanical Properties of E- Glass Short Fibres \& Fly Ash Reinforced Al 7075 Hybrid Metal Matrix Composites,"” Int. J. Appl. Res. Mech. Eng., vol. 2, no. 2, pp. 32-36, 2012.

[3] A. Atrian and G. Majzoobi, "CHARACTERIZATION OF AL7075-B 4 C COMPOSITE FABRICATED BY POWDER COMPACTION TECHNIQUES UNDER DIFFERENT," pp. 1-11, 2015.

[4] Q. Shen et al., "Microstructure and mechanical properties of Al-7075/ B 4 C composites fabricated by plasma activated sintering," J. Alloys Compd., vol. 588, pp. 265-270, 2014.

[5] N. Radhika, A. V. Vidyapeetham, and R. Raghu, "Tribology in Industry Evaluation of Dry Sliding Wear Characteristics of LM 13 Al / B 4 C Composites," no. April, 2015.

[6] V. R. Rao, N. Ramanaiah, and M. M. M. Sarcar, "Tribological properties of Aluminium Metal Matrix Composites ( AA7075 Reinforced with Titanium Carbide ( TiC ) Particles )," vol. 88, pp. 13-26, 2016.

[7] E. Zalnezhad and A. A. D. Sarhan, "A fuzzy logic predictive model for better surface roughness of Ti-TiN coating on AL7075-T6 alloy for longer fretting fatigue life," Meas. J. Int. Meas. Confed., vol. 49, no. 1, pp. 256-265, 2014.

[8] "Mechanical and Corrosion Behavior of A17075 ( Hybrid ) Metal Matrix Composites by Two Step Stir Casting Process," vol. 7075, pp. 243-255, 2016.

[9] R. Harichandran and N. Selvakumar, "Effect of nano/micro $B_{4} C$ particles on the mechanical properties of aluminium metal matrix composites fabricated by ultrasonic cavitationassisted solidification process," Arch. Civ. Mech. Eng., vol. 16, no. 1, pp. 147-158, 2016.

[10] A. A. Daniel, S. Murugesan, M. Manojkumar, and S. Sukkasamy, "Dry sliding wear behaviour of aluminium 5059/SiC/MoS 2 hybrid metal matrix composites," Mater. Res., vol. 20, no. 6, pp. 1697-1706, 2017.

[11] M. Nagaral et al., "Tensile Behavior of B 4 C Particulate Reinforced A12024 Alloy Metal Matrix Composites," pp. 93-96, 2017.

[12] J. Singh and A. Chauhan, "Characterization of hybrid aluminum matrix composites for advanced applications - A review," J. Mater. Res. Technol., vol. 5, no. 2, pp. 159-169, 2016.

[13] V. R. Rao, N. Ramanaiah, and M. M. M. Sarcar, "Dry Sliding Wear Behavior of TiC AA7075 Metal Matrix Composites," no. February, pp. 27-37, 2016.

[14] M. Subramanian, M. Sakthivel, K. Sooryaprakash, and R. Sudhakaran, "Optimization of end mill tool geometry parameters for A17075-T6 machining operations based on vibration amplitude by response surface methodology," Meas. J. Int. Meas. Confed., vol. 46, no. 10, pp. 4005-4022, 2013.

[15] N. B. Dhokey and K. K. Rane, "Wear behavior and its correlation with mechanical properties of TiB 2 reinforced aluminium-based composites," Adv. Tribol., vol. 2011, pp. $1-9,2011$. 